\title{
Clinical and laboratory profile of dengue fever in children from a tertiary care centre of Gandaki Province, Nepal
}

\author{
Namrata KC ${ }^{1}$, Krishna Bahadur Thapa ${ }^{2}$, Nirmala Shrestha ${ }^{3}$, Shankar Paudel ${ }^{1}$, Chandra Bahadur Pun ${ }^{2}$
}

'Department of Paediatrics, ${ }^{2}$ Department of Medicine, ${ }^{3}$ Department of Community Medicine, Gandaki Medical College Teaching Hospital, Pokhara, Nepal.

\begin{abstract}
Introduction: Dengue, the arthropod borne viral disease is serious public health problem in Nepal. The clinical diagnosis of dengue has become challenging in children as it is presented with nonspecific symptoms. The objective of present study was to assess different clinical presentations and outcomes of dengue fever in tertiary care centre. Methods: A record based observational cross-sectional study was carried out on all dengue positive patients of aged 11 months to 15 years presented in Gandaki Medical College from July to November 2019. Total 74 patients with history of fever with dengue seropositive were included in the study. All the clinical and haematological findings were recorded in semi-structured questionnaire form. Results: Of 74 patients 40 (54.1\%) males and 34 (45.9\%) were females. Fiftyone $(68.9 \%)$ were cases of dengue without warning sign, 18 (24.3\%) were dengue with warning signs and 5(6.8\%) cases had severe dengue symptoms. Most of the patients (78.38\%) were from Kaski district. Fever (100\%) was the most common clinical presentation followed by headache (36.5\%), vomiting (25.7\%), and retro orbital pain (20.3\%). Common laboratory findings included thrombocytopenia (59.4\%) and leukopenia (35.1\%). Among 74 cases, 68 were in stable condition and treated in OPD or in ward, and 6 were admitted in ICU of which one developed warning signs and other 5 had severe dengue. All the enrolled children recovered well and there was no mortality during this period. Conclusions: Fever, headache, vomiting, thrombocytopenia and leukopenia were most common presentation of dengue fever among children. Appropriate clinico-laboratory diagnosis and management is relatively simple, inexpensive and very effective in saving lives as long as correct and timely interventions are instituted.
\end{abstract}

Keywords: Severe dengue; Thrombocytopenia; Warning signs; WHO.

\section{Correspondence to:}

Dr. Namrata KC

Lecturer, Department of Paediatrics, Gandaki

Medical College Teaching Hospital, Pokhara, Nepal

Email:namukcpkr@gmail.com

Submitted: August 14, 2020

Accepted: November 30, 2020

To cite: KC N, Thapa KB, Shrestha N, Paudel S, Pun CB. Clinical and laboratory profile of dengue fever in children from a tertiary care centre of Gandaki Province, Nepal. JGMC Nepal. 2020;13(2):173-7.

DOI: $10.3126 /$ jgmcn.v13i2.30649

\section{INTRODUCTION}

Dengue fever is the most common arboviral febrile illness caused by flavivirus of four serotypes: DENV-1, DENV-2, DENV-3 and DENV-4. ${ }^{1}$ The spread of dengue is attributed to expanding geographic distribution of four dengue virus and their mosquito vectors predominantly by Aedes mosquito. ${ }^{2}$ The global prevalence of Dengue fever has grown dramatically in recent decades and outbreaks been reported from both developed and developing countries that is now classified as major health threat by WHO. ${ }^{3}$ WHO currently estimates 50 million cases of dengue infection worldwide every year. An estimated 500,00 cases are severe dengue infection require hospitalization each year, of which very large population are children. The WHO revised the guidelines for dengue disease classification in 2009 as Dengue without warning signs, Dengue with warning signs and Severe Dengue. ${ }^{3}$

DENV occurs in tropical and subtropical region worldwide with Asia always remaining as high endemicity. ${ }^{3,4}$ Nepal being 
surrounded by the India and China, the dengue endemic countries ${ }^{5,6}$ reported the first case of dengue disease in $2004{ }^{7,8}$ Major outbreaks occurred in 2010 with 917 cases and in 2013 with 683 cases and in 2016 with 1473 cases. $^{8-10}$ Since then the sporadic cases and the outbreaks suggestive of dengue fever illness is seen in Nepal from time to time. Dengue cases were initially reported from lowlands of southern Terai Nepal and has now expanded to urban highlands of Nepal like Kathmandu and Pokhara. ${ }^{11}$

Dengue fever is the self-limited disease but the mortality in severe dengue is as high as $20-30 \%$ if left untreated. ${ }^{3}$ Early recognition, careful monitoring and appropriate fluid therapy has resulted in reduction of case fatality with excellent outcome. The aim of our study was to assess clinical and laboratory profile and outcome of dengue cases in tertiary care centre of hilly region of Western Nepal for strategic alteration of public health programs.

\section{METHODS}

This was a record based observational study carried out in Paediatric department of Gandaki Medical College Teaching Hospital, tertiary centre. Seventy-four complete medical records of all laboratory confirmed dengue cases who were presented or admitted in Gandaki Medical College from $1^{\text {st }}$ July 2019 to $30^{\text {th }}$ November 2019 were retrieved. The clinical features with NS1 positive and/or IgM positive were labelled as Dengue confirmed. WHO classification and case definitions were used to classify the disease as Dengue without warning signs, Dengue with warning signs and Severe Dengue. ${ }^{3}$ Patients' demography, signs and symptoms, findings of laboratory investigation like complete blood counts, serum electrolytes, Liver function test, Renal function test, USG abdomen and pelvis, Chest $\mathrm{x}$-ray recorded in semi structured questionnaire forms. BeneSphera Dengue NS1 and IgG/ IgM rapid card test (lateral flow) kit was used for serology. Statistical analysis was done using SPSS 25. Descriptive analysis is expressed as numbers and percentage in tables. Median is calculated for quantitative variable (age).

\section{RESULTS}

Total number of cases was 74 , the minimum and maximum age of our respondent were 11 months and 15 years respectively with median age 10 years. Among the patients of Dengue Without Warning Signs, more than one-third (37.3\%) were from age group 8 to 11 years whereas $44.5 \%$ of patient of age group 12 years and more had Dengue With Warning Signs. Forty percent of patients with Severe Dengue were from age 8 to 11 years. The classification of dengue with gender distribution is shown in table 1 .

\section{Table: 1 Classification of Dengue cases with gender}

\begin{tabular}{lccc}
\hline Classification of Dengue & $\begin{array}{c}\text { Male } \\
\mathrm{n}(\%)\end{array}$ & $\begin{array}{c}\text { Female } \\
\mathrm{n}(\%)\end{array}$ & $\begin{array}{c}\text { Total } \\
\mathrm{n}(\%)\end{array}$ \\
$\begin{array}{l}\text { Dengue without warning sign } \\
26(51)\end{array}$ & $25(49)$ & $51(68.9)$ \\
Dengue with warning sign & $10(55.6)$ & $8(44.4)$ & $18(24.3)$ \\
Severe dengue & $4(80)$ & $1(20)$ & $5(6.8)$ \\
Total & $40(54.1)$ & $34(45.9)$ & $74(100)$ \\
\hline
\end{tabular}

Fifty-nine patients out of 74 were admitted in hospital. Out of them, 53(89.2\%) were admitted in ward and $6(10.2 \%)$ were admitted in ICU where 5 were Severe dengue and 1 was dengue with warning signs.

\section{Place distribution}

Most of the dengue cases were from Kaski district of ward no.9 followed by Tanahun, Syangja as shown below in the table 2 .

Table 2: Place distribution of the Dengue cases

\begin{tabular}{ccc}
\hline District & Number & Percentage \\
Kaski & 58 & 78.38 \\
Tanahun & 11 & 14.88 \\
Syangja & 3 & 4.05 \\
Baglung & 2 & 2.70 \\
Total & 74 & 100 \\
\hline
\end{tabular}

As the cases were more from ward no. 9 from Pokhara, effective program for preventive measures can be launched and enhance the knowledge of dengue among the population residing in these areas.

\section{Clinical findings of dengue in children}

Fever was present in all $(100 \%)$ the patients with headache (36.5\%), vomiting (25.7\%), and retro orbital pain (20.3\%) being the common symptoms of dengue in children as shown in Table:3.

Vomiting (100\%), Headache (60\%), Abdominal pain (60\%) were most common presenting symptoms and common signs were low blood pressure $(100 \%)$ and hepatomegaly (60\%) among Severe Dengue cases.

\section{Laboratory findings}

In dengue fever, common laboratory findings were thrombocytopenia, leukopenia and raised haematocrit level. NS1Ag positive cases were more as the most $(77 \%)$ of the patients were presented within 3 days of fever while 12.2 $\%$ of patient presented within 4-5 days of fever and $10.8 \%$ presented after 5 days of fever. 
Table: 3 Clinical presentation of Dengue cases and SEVERE Dengue

\begin{tabular}{lll}
\hline Clinical features & $\begin{array}{l}\text { Total dengue cases } \\
(\mathbf{n = 7 4 )} \\
\mathbf{n}(\%)\end{array}$ & $\begin{array}{l}\text { SEVERE Dengue } \\
(\mathbf{n}=5) \\
\mathbf{n}(\%)\end{array}$ \\
Fever & $74(100)$ & $5(100)$ \\
Headache & $27(36.5)$ & $3(60)$ \\
Vomiting & $19(25.7)$ & $5(100)$ \\
Abdominal Pain & $11(14.9)$ & $3(60)$ \\
Retro-orbital pain & $15(20.3)$ & $2(40)$ \\
Myalgia & $12(16.2)$ & $1(20)$ \\
Rash & $9(12.2)$ & 0 \\
Hepatomegaly & $9(12.2)$ & $3(60)$ \\
Hypotension & $5(6.8)$ & $5(100)$ \\
\hline
\end{tabular}

Among Severe Dengue, the common laboratory findings were thrombocytopenia, leukopenia, raised alkaline transaminases, and raised haematocrit level.

Table:4 Laboratory findings on dengue types (column total)

\begin{tabular}{|c|c|c|c|c|c|}
\hline \multicolumn{2}{|c|}{ Laboratory Test } & \multirow{2}{*}{$\begin{array}{c}\begin{array}{c}\text { Dengue } \\
\text { without } \\
\text { warning( } n=51) \\
\mathbf{n}(\%)\end{array} \\
13(25.5)\end{array}$} & \multirow{2}{*}{ 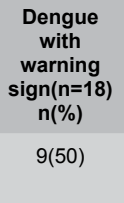 } & \multirow{2}{*}{$\begin{array}{c}\begin{array}{c}\text { Severe } \\
\text { dengue } \\
(\mathbf{n}=5)\end{array} \\
\mathrm{n}(\%)\end{array}$} & \multirow{2}{*}{$\begin{array}{l}\text { Total } \\
N=74 \\
n(\%)\end{array}$} \\
\hline $\begin{array}{c}\text { Total } \\
\text { Leukocytes }\end{array}$ & $\begin{array}{l}\text { Leukopenia } \\
\quad<4000\end{array}$ & & & & \\
\hline $\begin{array}{l}\text { count } \\
\text { cell/mm }\end{array}$ & $\begin{array}{c}\text { Normal } \\
(4000-11000)\end{array}$ & $38(74.5)$ & $9(50)$ & $1(20)$ & $48(64.8)$ \\
\hline ALT & $\begin{array}{l}\text { Normal } \\
(0-40)\end{array}$ & 47 (92.2) & $17(94.4)$ & $1(20)$ & $65(87.9)$ \\
\hline OIL & High $(>40)$ & $4(7.8)$ & $1(5.6)$ & $4(80)$ & $9(12.1)$ \\
\hline \multirow{3}{*}{$\begin{array}{l}\text { Total Platelet } \\
\text { count } / \mathrm{mm} 3\end{array}$} & $\begin{array}{c}>1.5,00,000 / \\
\mathrm{mm} 3\end{array}$ & $19(37.3)$ & $5(27.8)$ & 0 & $24(32.4)$ \\
\hline & $\begin{array}{l}1,00,000- \\
1,50,000\end{array}$ & $23(45.1)$ & $9(50)$ & $2(40)$ & $34(45.9)$ \\
\hline & $\begin{array}{l}75,000- \\
99,000\end{array}$ & $9(17.6)$ & $1(5.6)$ & 0 & $10(13.5)$ \\
\hline \multirow{5}{*}{ Hematocrit } & $<75000$ & 0 & $3(16.7)$ & $3(60)$ & $6(8.10)$ \\
\hline & $30.1-35 \%$ & $4(7.8)$ & $4(22.2)$ & 0 & $8(10.8)$ \\
\hline & $35.1-40 \%$ & $28(54.9)$ & $7(38.9)$ & $4(80)$ & $39(52.7)$ \\
\hline & $40.1-45 \%$ & 19(37.3) & $7(38.9)$ & $1(20)$ & $27(36.5)$ \\
\hline & NS1 & $43(84.3)$ & $13(72.2)$ & $1(20)$ & $57(77)$ \\
\hline \multirow{2}{*}{$\begin{array}{l}\text { Serology } \\
\text { positivity }\end{array}$} & IgM, NS1 & $5(9.8)$ & $5(27.8)$ & $3(60)$ & $13(17.6)$ \\
\hline & $\lg M$ & $3(5.9)$ & 0 & $1(20)$ & $4(5.4)$ \\
\hline
\end{tabular}

\section{Management and Outcome}

Among 74 cases, 68 cases were in stable condition and treated on OPD basis or in ward, and 6 were admitted in ICU and treated. All the enrolled children recovered well and there was no mortality during this period. Hence, the early recognition of signs and symptoms of dengue fever is very important for successful outcome.

\section{DISCUSSION}

Global incidence of dengue fever has increased dramatically in the recent decades. ${ }^{6}$ There are very few studies based on the revised new dengue classification. Based on the
WHO TDR 2009 dengue guidelines, in our study, the total number of cases analysed was 74, out of which 51(68.5\%) were categorized as cases of Dengue without warning signs, $18(24.3 \%)$ were Dengue with warning signs and 5 $(6.80 \%)$ were cases of Severe dengue which was similar to the observation made in the study done in south Rajasthan, India. ${ }^{12}$ The maximum numbers of cases were seen in the group $>8$ years of age and the least affected age group was infants which was similar to study done by Mishra et al. ${ }^{13}$ Gender distribution of cases showed there were 40 (54.1\%) males and 34 (45.9\%) females in our study which similar to study done by Moinuddin et al. ${ }^{14}$

Regarding symptoms, in our study fever was present in all the patients with headache, vomiting, and retro orbital pain being the common symptoms in dengue fever which is concordant with study done by Banerjee et al. ${ }^{15}$

In this study low platelet count, and leukopenia were observed which important clues to the diagnosis of dengue fever. Elevated liver enzymes were observed in all patients with Severe Dengue had similar high values of enzymes was noted in previous studies done in southern India. ${ }^{16}$

Our study also showed that in Severe Dengue, Vomiting (100\%), Abdominal pain (60\%) were most common presenting symptoms and low blood pressure (100\%), hepatomegaly $(60 \%)$ were common physical findings .Similarly,80 \% had leukopenia and $60 \%$ had platelet count less than $75000 \mathrm{~mm} / 3$ among Severe Dengue cases. These finding are concordant with the study done by Pothapregada et $\mathrm{al}^{17}$ and Jairaj et al.$^{18}$

In our study, more than three-fourth $(77 \%)$ of patients were positive for only NS1 followed by NS1 and IgM were (17.6\%) and IgM only were (5.4\%) as most $(77 \%)$ of the patients were presented within 3 days of fever while $12.2 \%$ of patient presented within 4-5 days of fever and $10.8 \%$ presented after 5 days of fever. Non-Structural protein 1 antigen positive indicate high sensitivity of the test for early diagnosis of disease.as in the study of Jain et al $^{12}$ and Kumarasamy et al. ${ }^{19}$

In our study, most of the dengue cases were from Kaski district of ward no.9 followed by Tanahun, Syangja and the reason for it may be that our hospital is in Kaski district ward no.8 so more the nearby patients visited the hospital and the other reason may be that the bus park area and slum areas are more in this ward.

Among 74 cases, no mortality was observed during this study period. In our study 68 cases were in stable condition and treated on OPD basis or in ward, and 6 were admitted in ICU as had severe dengue. The overall mortality of 
dengue infection is low if treated appropriately, however the mortality associated with severe dengue is high as these patients need ICU settings and ventilator support which is not available in every health care facility. The knowledge regarding its presentation, clinical and biochemical features and best management practices are the key to successfully manage these patients. Similarly, public awareness regarding preventive strategies is essential to fight against this disease

\section{CONCLUSIONS}

Children with the median age of 10 years was commonly affected by dengue. Fever, headache, vomiting, thrombocytopenia and leukopenia were common clinicallaboratory finding in dengue cases. Children with these findings in Gandaki province should be suspected of having dengue fever and managed accordingly. Our document will hopefully be useful to Nepalese government agencies to help strengthen mosquito surveillance and disease diagnosis and treatment programs.

\section{Acknowledgement}

The authors would like to express deep thanks and sincere appreciation to all the faculty members of department of paediatrics, Gandaki Medical College and Teaching Hospital for their support.

\section{Conflict of interest: none}

\section{REFERENCES}

1. Gupta BP, Lamsal M, Chaulagain S, Rauniyar R, Malla $\mathrm{R}$, Shrestha S, et al : Emergence of dengue in Nepal. Virusdisease. 2018 Jun;29(2):129-33. doi: 10.1007/ s13337-018-0439-3 PMID: 29911144.

2. Rodenhuis-Zybert IA, Wilschut J, Smit JM. Dengue virus life cycle: viral and host factors modulating infectivity. Cell Mol Life Sci. 2010 Aug;67(16):2773-86. 10.1007/ s00018-010-0357-z PMID: 20372965.

3. Dengue: Guidelines for diagnosis, treatment, prevention and control. World Health Organization. Geneva, Switzerland: WHO; 2009.

4. WHO. Comprehensive guidelines for prevention and control of dengue and dengue haemorrhagic fever. WHO Regional Publication SEARO. 2011:159-68

5. Pol S, Rajderkar S, Bansode-gokhe S. Where and how the dengue vector control program should focus its attention? - A study from Metropolitan City of Maharashtra. Int J Mosq Res. 2017;4(4):107-11.

6. Wang X-J, Jiang S-C, Wei H-X, Deng S-Q, He C, Peng H-J. The Differential Expression and Possible Function of
Long Noncoding RNAs in Liver Cells Infected by Dengue Virus. Am J Trop Med Hyg. 2017 Dec;97(6):1904-12. doi: 10.4269/ajtmh.17-0307 PMID: 29016307.

7. Malla S, Thakur GD, Shrestha SK, Banjeree MK, Thapa LB, Gongal G, et al. Identification of all dengue serotypes in Nepal. Vol. 14, Emerging infectious diseases. 2008;14:1669-70. doi: 10.3201/eid1410.080432 PMID: 18826846.

8. Pandey BD, Morita K, Khanal SR, Takasaki T, Miyazaki I, Ogawa $\mathrm{T}$, et al. Dengue virus, Nepal. Emerging infectious diseases. 2008;14:514-5. doi: 10.3201/ eid1403.070473 PMID:18325280.

9. Singh S, Gupta BP, Manakkadan A, Das Manandhar K, Sreekumar E. Phylogenetic study reveals co-circulation of Asian II and Cosmopolitan genotypes of Dengue virus serotype 2 in Nepal during 2013. Infect Genet Evol J Mol Epidemiol Evol Genet Infect Dis. 2015 Aug;34:402-9. doi: 10.1016/j.meegid.2015.07.006 PMID: 26160542.

10. Subedi D, Taylor-Robinson AW. Epidemiology of dengue in Nepal: History of incidence, current prevalence and strategies for future control. J Vector Borne Dis. 2016 Mar;53(1):1-7.

11. Thapa S, Pant ND, Shrestha R, Gc G, Shrestha B, Pandey $\mathrm{BD}$, et al. Prevalence of dengue and diversity of cultivable bacteria in vector Aedes aegypti (L.) from two dengue endemic districts, Kanchanpur and Parsa of Nepal. J Health Popul Nutr. 2017;36(1):5. doi: 10.1186/s41043017-0080-6 PMID: 28193261.

12. Jain H. Clinical profile and outcome of dengue fever in hospitalized children of South Rajasthan, India. Int J Contemp Pediatr. 2016;3(2):546-9. doi: 10.18203/2349-3291.ijcp20161035

13. Mishra S, Ramanathan R, Agarwalla SK. Clinical Profile of Dengue Fever in Children: A Study from Southern Odisha, India. Scientifica (Cairo). 2016;2016:6391594. Epub 2016 Apr 24. doi: 10.1155/2016/6391594. PMID: 27213083.

14. Moinuddin MK, Sahana Devadas SD. Clinical profile and outcome of dengue fever in a paediatric tertiary care centre. Int J Contemp Pediatr. 2017;4(3):875. doi: 10.18203/2349-3291.ijcp20171689

15. Banerjee A, Barik KL, Bandyopadhyay A, Paul UK. A study on the clinical features of dengue virus infected pediatric patients. Int J Contemp Pediatr. 2018;5(2):368. doi: 10.18203/2349-3291.ijcp20180437

16. Sahana KS, Sujatha R. Clinical Profile of Dengue Among 
Children According to Revised WHO Classification: Analysis of a 2012 Outbreak from Southern India. Indian J Pediatr. 2015;82(2):109-13. doi: 10.1007/ s12098-014-1523-3 PMID: 24986196.

17. Pothapregada S, Sivapurapu V, Kamalakannan B, Thulasingham $M$. Role of early warning signs in children with severe dengue infection. Int J Contemp Pediatr. 2018;5(4):1423. doi: 10.18203/2349-3291. ijcp20182540

18. Jairaj S, Sridhar D, Reddy MP. Clinical, laboratory and radiological profile of dengue among pediatric patients admitted in tertiary care hospital. Int J Community Med Public Heal. 2018;5(6):2237. doi: 10.18203/23946040.ijcmph20181969

19. Kumarasamy V, Wahab AHA, Chua SK, Hassan Z, Chem YK, Mohamad M, et al. Evaluation of a commercial dengue NS1 antigen-capture ELISA for laboratory diagnosis of acute dengue virus infection. J Virol Methods. 2007 Mar;140(1-2):75-9. doi: 10.1016/j. jviromet.2006.11.001 PMID: 17140671. 